\title{
Comparación de las técnicas PCR anidado y Rosa de Bengala para la detección de Brucella spp. en bovinos
}

\author{
Orly Cevallos ${ }^{1}$, Ariel Escobar ${ }^{1}$, Mercedes Carranza ${ }^{1}$, Silvia Saucedo ${ }^{1}$, Diego Romero, \\ Ximena Reyes ${ }^{1}$, Samir Zambrano ${ }^{1}$.
}

${ }^{1}$ Unidad de Investigación, Laboratorio de Biotecnología, Universidad Técnica Estatal de Quevedo. Quevedo, Los Ríos, Ecuador. orlycevallos@hotmail.com

Recibido: 05, 05, 2011; aprobado: 26, 09, 2011

\begin{abstract}
RESUMEN.- Para comparar la técnica de PCR anidado frente a la prueba serológica Rosa de Bengala (RB) en la detección de Brucella spp. se utilizó 40 muestras de sangre, de cuatro hatos de bovinos con alta prevalencia de brucelosis en la región central de Ecuador. E1 35\% de los animales dio positivo para el análisis con RB, mientras que con PCR simple fue del $45 \%$ con una correlación del $30 \%$, lo que sugiere que la PCR frente a la RB es $22 \%$ más sensible. El análisis de correlación de los animales positivos obtenidos entre PCR y PCR anidado fue del $100 \% \mathrm{y}$, la sensibilidad del PCR anidado demostró el 37,9\% superior a la PCR. Entre RB y PCR anidado, la correlación de sensibilidad fue del 51,7\% superior para la segunda. La detección de los animales positivos mediante PCR y PCR anidado se mostró más específica y sensible que RB, por lo tanto en este trabajo se considera al PCR anidado como una herramienta molecular útil en el diagnóstico de Brucella spp. y su uso en la prevención de la enfermedad.
\end{abstract}

PALABRAS CLAVE: Brucelosis, correlación, diagnóstico, enfermedad, prevalencia.

ABSTRACT .- Forty blood samples from 4 herds with high prevalence of brucellosis in the central region of Ecuador were used in order to compare the nested PCR with the serological Rose Bengal (RB) tests for the detection of Brucella spp. Thirty five $\%$ of the animals were detected positive with the RB analysis and $45 \%$ with simple PCR, with a correlation of $30 \%$, suggesting that PCR was $22 \%$ more sensitive than the RB serological method. Correlation analysis of positive animals obtained with PCR and with nested PCR was $100 \%$ but sensitivity of nested PCR was $37.9 \%$ higher than PCR. Correlation sensitivity between RB and nested PCR 
was $51.7 \%$ higher for PCR. The detection of positive animals with PCR and with nested PCR was more sensitive and probably more specific. This paper considers the nested PCR as a useful molecular tool in the diagnosis of Brucella spp. and its use in the prevention of disease.

KEYWORDS: Brucellosis, correlation, diagnosis, disease, prevalence.

\section{INTRODUCCIÓN}

La brucelosis es una patología zoonótica de distribución mundial. Actualmente el gran número de animales bovinos portadores de la bacteria responsable complica en gran medida las acciones de lucha contra esta infección, en especial las preventivas, ya que tanto su prevalencia como la de los posibles vectores que colaboran en su amplia diseminación no se encuentran claramente establecidas (1). Por otra parte, la brucelosis no presenta un cuadro clínico característico que permita una detección precoz del animal infectado, lo que favorece la evolución a la cronicidad, complicando las alternativas terapéuticas y la curación definitiva de los animales (2). Concurrentemente, la detección de esta zoonosis es basada sobre pruebas de laboratorio serológicas y microbiológicas. El patógeno puede ser detectado en cultivos de sangre, lo cual representa la "prueba de oro" en el diagnóstico de laboratorio, sin embargo, la sensibilidad de esta técnica es baja, el rango va desde el $15 \%$ al $70 \%$, además de requerir un largo período de incubación y representa un gran riesgo de in- fección para los técnicos del laboratorio (3). El diagnóstico valorado sobre ensayos de anticuerpos es insatisfactorio en estadios tempranos, debido a la baja sensibilidad, reacción cruzada serológica y la inhabilidad para distinguir entre la infección activa e inactiva, debido a la persistencia de anticuerpos después de la terapia (4).

El diagnóstico de la brucelosis animal mediante observaciones clínicas por análisis microbiológicos no es confiable, debido a las dificultades que presenta los diferentes niveles de infección. Además, debido a la posibilidad de reacciones cruzadas con otras bacterias, la presencia de anticuerpos o la existencia de una respuesta celular en un determinado animal no significan necesariamente que éste experimente una infección activa por Brucella. Por ello, los resultados de los diagnósticos directos o indirectos no se correlacionan efectivamente con los datos clínicos de la enfermedad, por lo que hay más certeza cuando los resultados son comparados con los análisis moleculares como la (PCR) Reacción en Cadena de la Polimerasa (5). 
En el presente trabajo se da a conocer el desarrollo y la implementación de la técnica molecular de PCR anidado, como una herramienta potencial para el diagnóstico de Brucella spp. Además, se contrastaron los resultados del análisis molecular versus los resultados del tamizaje por Rosa de Bengala, empleando muestras de sangre provenientes de bovinos de zonas cercanas al cantón Quevedo en la provincia de Los Ríos, Ecuador.

\section{MATERIALES Y MÉTODOS}

Toma de muestras.- Las muestras de sangre de bovinos fueron recolectadas en las haciendas San Pedro y San Jorge, El Carmen y vía Chone respectivamente (Prov. de Manabí), Bella SiriaQuevedo (Prov. de Los Ríos) y la hacienda Pacaritambo-El Empalme (Prov. del Guayas). Se utilizaron 40 animales entre machos y hembras de los cuales se tomaron $3 \mathrm{ml}$ de sangre total para el análisis serológico RB (6) y molecular. Se trabajó con dos cepas bacterianas puras C19 (vacunal) y C119 (antígeno) de Brucella spp. conferidas por el Instituto Nacional de Higiene "Leopoldo Izquieta Pérez". Estas cepas fueron cultivadas en cajas Petri con agar de tripticasa de soya y papa a $37^{\circ} \mathrm{C}$ por 48 horas.

Rosa de Bengala.- Se colocaron 0,03 $\mathrm{ml}$ de plasma o suero sobre uno de los cuadrados de la lámina de vidrio (porta objeto). Luego, se colocó una gota ( 0,03 $\mathrm{ml})$ de antígeno Rosa de Bengala (Card
Test) cerca de la gota del suero, se mezcló el suero con el antígeno utilizando un agitador o monadiente distinto para cada muestra. La superficie ocupada por la muestra fue de un diámetro de 23 a $24 \mathrm{~mm}$, se giró la lámina durante $4 \mathrm{~min}$ a razón de 10 a 12 movimientos por minuto de forma manual. El resultado de la prueba se pudo leer a los cuatro minutos sobre un fondo blanco. Las reacciones positivas presentaron grumos de aglutinación, que pueden ser grandes o pequeños. La prueba es cualitativa, por lo que el resultado se informó como positivo o negativo.

Extracción de ADN y PCR.- Las extracciones de ADN para sangre fueron procesadas utilizando el método de TENS (50 mM de Tris-HCl, $50 \mathrm{mM}$ de EDTA, $100 \mathrm{mM}$ de $\mathrm{NaCl}$ y $1 \%$ de SDS) (7) y miniprep para bacterias (9).

Se diseñaron dos juegos de oligonucleótidos (Blast, Primer3, Vector NTI Suite 11.5) dirigidos a la secuencia $16 \mathrm{~S}$ ARNr que fueron publicados en el EMBL-X13695 del GenBank (Tabla 1).

La implementación de la reacción en cadena de la polimerasa se realizó a partir del protocolo estándar (8); tomando en cuenta la temperatura de hibridación del fabricante para cada juego de iniciador. De cada producto de ADN amplificado se tomó $10 \mu \mathrm{l}$ y se mezcló con 3 ¡1 de tampón de depósito $(13,3 \%(\mathrm{v} / \mathrm{v})$ glicerol, 3,3\% (p/v) azul de bromofenol) para depositar en un gel horizontal de agarosa al $2 \%(\mathrm{p} / \mathrm{v})$ y se le agrego $4 \mu \mathrm{l}$ 
de bromuro de etidio $(0.5 \mu \mathrm{g} / \mathrm{ml})$. Se migró (75 V durante $40 \mathrm{~min}$ ) conjuntamente con un marcador peso molecular de $100 \mathrm{pb}$ (Gibco BRL) para corroborar el tamaño de las bandas obtenidas. Luego se visualizaron los productos de ADN utilizando un transiluminador de UV y se fotodocumentó.

\section{RESULTADOS}

Extracción de ADN.- Se logró obtener buena cantidad y calidad de ADN, determinando un promedio de $60 \mathrm{ng} / \mu \mathrm{l}$ de ADN para cada una de las muestras.

Evaluación de los oligonucleótidos.- Utilizando como fuente de ADN la cepa $\mathrm{C} 19$, se probaron varias temperaturas de hibridación. Para AB1, AR2, BRU-2F y BRU-2R, se amplifico dos bandas bien definidas de 725 pb y 225 $\mathrm{pb}$ respectivamente, lo que confirmó los tamaños esperados al análisis de la secuencia de Brucella spp. (Figura 1).

Comparación de la PCR versus el PCR anidado.- Para el desarrollo de estas pruebas se utilizó diluciones seriadas de ADN obtenidos a partir de la cepa C19, estos mismos amplicones fueron utilizados para el PCR anidado (Figura 2).

En nuestros análisis la sensibilidad de detección el PCR anidado fue $10^{4}$ veces mayor que la PCR estándar.

Correlación entre las técnicas moleculares (PCR/PCR anidado) y la técnica serológica (RB).- La tabla dos indica, que del total de muestras anali- zadas, un promedio del $35 \%$ dio positivo con el análisis de $\mathrm{RB}$, mientras tanto que con PCR fue del 45\%, el índice de correlación entre RB versus PCR dio un promedio del $30 \%$, lo que sugiere que la técnica molecular de PCR es $22 \%$ más sensible a la detección de Brucella spp. Por otro lado, las muestras negativas y positivas obtenidas por PCR se pudo amplificar por PCR anidado, demostrando una correlación del $100 \%$ entre las dos, además el índice de sensibilidad para la detección de Brucella spp. por PCR anidado fue $37,9 \%$ más sensible que la PCR. En cuanto a la relación de las técnicas de RB y PCR anidado el índice de sensibilidad de detección de esta última es 51,7\% superior (Tabla 2).

\section{DISCUSIÓN}

En el marco de estudio de la brucelosis, se han publicado hasta la fecha al menos 400 trabajos basados sobre métodos de PCR para la detección de Brucella spp, apoyados en secuencias de los genes 16S ARNr (8), omp2a (10), BCSP31 $(11,13,14,15)$. Los datos obtenidos y bibliográficos demuestran que la elección de iniciadores no afecta la sensibilidad de la prueba $(8,10,13$ ,16), quienes han utilizado esta técnica en muestras de sangre, han presentado resultados similares a los que hemos obtenido molecularmente.

Inicialmente, se analizaron todas las muestras con la prueba serológica Rosa de Bengala, la cual según datos mostra- 
dos tuvo un alto índice de detección de casos falsos negativos respecto a la PCR. Esto se debe posiblemente a que cuando la Brucella spp. penetra en el organismo es fagocitada por los leucocitos polimorfonucleares $(\mathrm{PMN})$ y los macrófagos tisulares, donde puede multiplicarse en su interior, localizándose finalmente en los órganos del sistema retículo endotelial y el nivel de bacterias sea no detectada (15). Otra de las vías puede ser en la producción de anticuerpos específicos, en cuanto a su magnitud y a su utilización en el diagnóstico serológico de la enfermedad, pero al ser una bacteria de tipo intracelular tiene una capacidad protectora limitada. La primera inmunoglobulina que se produce es la IgM, sus niveles comienzan a disminuir alrededor de los tres meses del inicio de la enfermedad. A partir de la segunda semana se elevan la IgG y la IgA que pueden permanecer incrementadas durante un largo período de tiempo con independencia de la evolución clínica de la enfermedad, por lo que la RB reconoce IgM (6). No se puede descartar la posibilidad de diagnosticar Brucella spp. en animales seronegativos y que por las razones anteriormente comentadas, no fueron positivos en la inmunoprueba RB $(6,17)$.

Existen varias posibles explicaciones sobre la ocurrencia de animales positivos con RB y negativos por PCR. En primer lugar, la presencia de factores transmenbranales de otras bacterias gramnegativas (Escherichia coli, Vibrio cholerae; etc.), que pueden ser reconocidos por el antígeno de RB. Esta podría ser una de las causas de que se obtengan resultados positivos con RB y PCR negativas (4). Otros autores sugieren que la RB son pruebas no útiles para el diagnóstico de la infección por Brucellas spp. por ser deficientes en la cadena $\mathrm{O}$ del LPS (5).

Por otro lado, los estudios realizados $(12,16,18,19,20)$ proponen que el uso de la PCR en muestras de sangre ha sido más precisa en la detección de Brucella spp. que las técnicas serológicas, lo que se ajusta con los resultados obtenidos en este trabajo. En la actualidad, se conoce que las pruebas serológicas son poco confiables cuando los animales se encuentran en la etapa intermedia de la infección, pero sin embargo son utilizadas en el campo por su bajo costo pero poco efectivo (21).

La creación de nuevas herramientas de análisis permite efectivizar el diagnóstico en animales y, en el hombre por la relación zoonósica que presenta la bacteria. En este trabajo se logró implementar el primer estudio analítico por la técnica de PCR y PCR anidado para la detección de la Brucella ssp. en poblaciones de bovinos en tres zonas del Ecuador.

\section{CONCLUSIONES}

Se pudo obtener un buen protocolo de extracción de ADN a partir de muestras de sangre de bovino. 


\section{$\begin{array}{llllllll}\text { MPM } & \mathrm{C}-1 & 1 & 2 & 3 & 4 & \mathrm{CE} & \mathrm{C} 2\end{array}$}

$725 \mathrm{pb}$

225pb

Figura 1. Gel de electroforesis con productos de amplificación de Brucella spp. MPM, marcador de peso molecular; C-1, control negativo de extracción de ADN; línea 1, PCR de C19; 2, PCR de animal con signos clínicos de brucelosis; 3 y 4, PCR anidado de 1 y 2; CE y C-2, controles de los reactivos de la PCR y PCR anidado respectivamente.

PCR

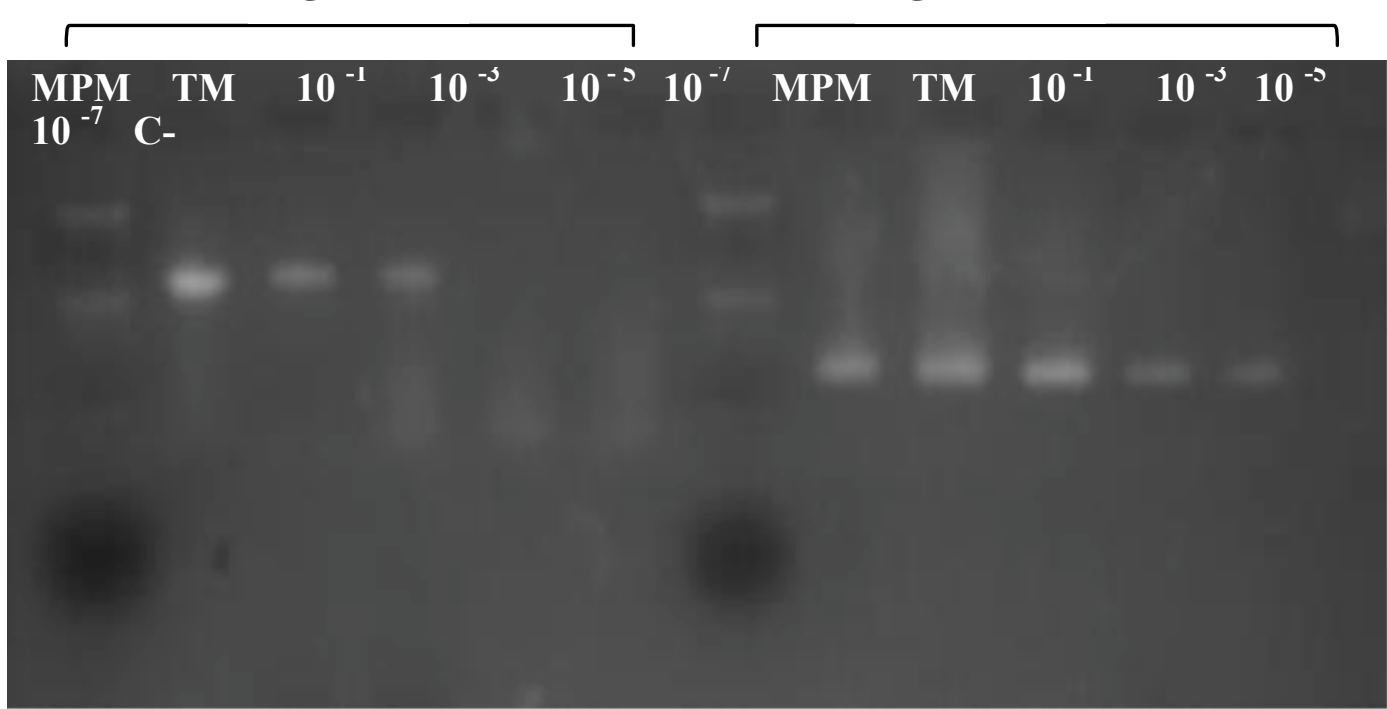

Figura 2: Nivel de amplificación de PCR y PCR anidado en diluciones seriadas de ADN desde $10^{-1}$ hasta $10^{-7}$. 
Tabla 1. Análisis de los iniciadores con Vector NTI Suite 11.5.

\begin{tabular}{|c|c|c|c|}
\hline Iniciadores & Secuencia & $\operatorname{Temp}\left({ }^{\circ} \mathrm{C}\right)$ & $\begin{array}{c}\text { Hairpin \& } \\
\text { Dímeros }\end{array}$ \\
\hline AB 1 & 5'-GCGACGATCCATAGCTG-3' & 52.9 & 1 \\
\hline AR2 & 5’AACCATAGTGTCTCCACTAA-3' & 50.2 & 2 \\
\hline BRU-2F & 5'GTGGGGAGCAAACAGGATTA 3' & 54.8 & 0 \\
\hline BRU-2R & 5'CAAGGGCTGGTAAGGTTCTG 3' & 55.6 & 0 \\
\hline
\end{tabular}

Tabla 2. Resultados porcentuales de correlación entre las técnicas moleculares (PCR y PCR anidado) y serológica (RB).

\begin{tabular}{lccccc}
\hline HACIENDAS & RB & RB vs PCR & PCR & PCR vs PCR-A & PCR-A \\
\hline Pacaritambo & 50 & 50 & 60 & 100 & 100 \\
Bella Siria & 30 & 30 & 40 & 100 & 70 \\
San Pedro & 30 & 30 & 40 & 100 & 70 \\
San Jorge & 30 & 10 & 40 & 100 & 50 \\
Promedio & 35 & 30 & 45 & 100 & 72.5 \\
\hline
\end{tabular}

El PCR anidado permitió optimar los resultados que fueron analizados con la técnica serológica tradicional Rosa de Bengala y PCR simple.

Por su sensibilidad, especificidad y rapidez (seis horas) el PCR anidado podría ser una herramienta efectiva a emplearse para el diagnóstico de la brucelosis en Ecuador, ya que la técnica convencional Rosa de Bengala no presenta estas ventajas.

Hasta la publicación de este documento, no hay registro de un estudio com- parativo en bovinos sobre la detección y correlación de Brucella ssp. a partir de muestras de sangre, utilizando técnicas moleculares versus la técnica serológica tradicional Rosa de Bengala en Ecuador.

\section{REFERENCIAS}

\section{BIBLIOGRÁFICAS}

1. BLASCO, J. M. 1990. Brucella ovis. In: Nielsen, K., Duncan, J.R. (Eds.), Animal Brucelosis. CRC Press, Boca Raton, FL, pp. 351378. 
2. DIAZ, R. \& MORIYÓN I. 1989. Laboratory techniques in the diagnosis of human brucellosis. In: Brucellosisi: Clinical and Laboratory Aspects. Young EJ, Corbel MJ (Eds),CRC Press, FL, USA,73-83 (1989).

3. YOUNG, E. J. 1997. Especies de Brucella. In: Enfermedades Infecciosas Principios y práctica. Mandell GL, Douglas RG, Bennett JE (Eds), Medica Panamericana, Buenos Aires, Argentina, 23002307.

4. AL - ATTAS, R. A.; AL -KHALIFA M.; AL- QURASHI A.R.; BADAW ${ }_{1}^{r}$ i 1 . Y AL- GUALY. 2000. Evaluation of PCR culture and serology for the diagnosis of acute human brucellosis. Ann. Saudi. Med. 20 (3): 224 - 228.

5. BUSTAMANTE, S. J.; SALAZAR H.F.; DIAZ A. E.; MANZANO, C.C.; PEREZ, G.R; \& HERNÁDEZ, A. L. 2000. Estudio bacteriológico y serológico de brucelosis en vacas revacunadas con dosis reducida de cepa C19 de Brucella spp.. Tec. Pecuria. Mex. 38(1): 3542.

6. ALTON, G. G.; JONES, L. M.; ANGUS, R. D. \& VERGER I.M. 1988. Techniques for the Brucellosis.30. Laboratory Imprimerie Louis Jean, París.

7. FERREIRA, C. R.; AMORES, S.I. 2009. Extracción de ADN a partir de Muestras de Biopsias. Disponible en la página de internet. Consultado en marzo del 2009.

8. ROMERO, C.; PARDO, M.; GRILLO, J. M.; et al. 1995B. Evaluation of PCR and Indirect EnzymeLinked Immunosorbent Assay on Milk Samples for Diagnosis of Brucellosis in Dairy Cattle. 33:12 3198-3200.

9. MOSQUERA, X.; BERNAL, C.; MUSKUS L. 2008. Detection of Brucellas spp. in blood and milk of dairy cattle by PCR method. Rev.MVZ Córdoba 13(3):15041513.

10. LEAL-KLEVEZAS, D. S.; MARTÍNEZ-VÁSQUEZ, I. O.; GARCÍA-CANTU.; et al. 2000. Use of polymerase chain reaction to detect Brucella spp. biovar 1 in infected goats. Veterinary Microbiology $\mathbf{7 5}$, 91-97.

11. BAILY, G. G.; J. B. KRAHN, B. S.; DRASAR, Y. N. G.; STOKER. 1992. Detection of Brucella melitensis and Brucella spp. by DNA amplification. J. Trop. Med. Hyg. 95: 271-275.

12. MATAR, G. M.; KHNEISSER I. A; ABDELNOOR, A. M.; 1996. Rapid laboratory confirmation of human brucellosis by PCR analysis of a target sequence on the $31-\mathrm{Ki}$ lodalton antigen DNA. J. Clin. Microbiol. 34, 477-478. 
13. QUEIPO-ORTUÑO, M. I.; MORATA, P.; OCON P.; et al. 1997. Rapid diagnosis of human brucellosis by peripheral-blood PCR assay, J. Clin. Microbiol. 35, 29272930.

14. MORATA, P.; QUEIPO-ORTUÑO, I. M.; COLMENERO, D. J. 2001B. PCR Assay for Dignosis of Human Brucellosis. P.1654 - 1655.

15. MOSQUERA, X.; BERNAL, C.; MUSKUS, L. 2008. Detection of Brucellas spp. in blood and milk of dairy cattle by PCR method. Rev. MVZ Córdoba 13(3):1504-1513.

16. SREEVATSAN, S.; BOOKOUT, B. J.; RINGPIS F, et al. 2000. A Multiplex Approach to Molecular Detection of Brucella spp. and/or Mycobacterium bovis Infection in Cattle. J. Clin. Microbiol. 38. 26022610.

17. COLMENERO, J. D \& MORATA P. 2001. Specificity of a Polymerase Chain Reaction Assay of a Target Sequence on the 31 - Kilodalton Brucella Antigen DNA Used to Diagnose Human Brucellosis. Journal of Clinical Microbiology.20: $127-131$.
18. MARTÍNEZ, O. I.; VÁSQUEZ, P. B.; MONTES, M. F, et al. 2000. Diagnóstico Simultáneo de brucelosis y tuberculosis mediante PCR múltiples. Vol. 25 No. 2 Pág.53-57.

19. MARTÍNEZ-SORÍANO, J. P.; CAB-BARRERA, E. L.; TAMEZGONZÁLEZ, R, et al. 1993. Detección de Brucella spp. por medio de la reacción en cadena de la polimerasa. Bioquímica. 18, 10-16.

20. MORATA, P.; QUEIPO-ORTUNO, I. M.; REGUERA, M. J.; et al. 2001A. Diagnostic Yield of a PCR Assay in Focal Complications of Brucellosis. 39:10 3743-3746.

21. CORBEL, M. J.; BRINLEY-MORGAN, W. J. 1984. Genus Brucella, p. 377-388. En: N. R. Krieg (ed.), Bergey's manual of systematic bacteriology, vol. 1. Williams y Wilkins, Baltimore, Md.

22. LEAL-KLEVEZAS, D. S; MARTÍNEZ-VÁSQUEZ, I. O.; LÓPEZMERINO, A.; et al. 1995B. Single step PCR for the detection of Brucella spp. From blood and milk of infected animals. J. Clin. Microbiol. 33, 3087-3090. 